\title{
The Relationship Between rs3212986C>A Polymorphism and Tumor Stage in Lung Cancer Patients
}

Ali Arash Anoushirvani ${ }^{1}$, Reza Aghabozorgi ${ }^{1}$, Azam Ahmadi ${ }^{2}$, Mohammad Arjomandzadegan ${ }^{3}$, Sara Khalili ${ }^{4}$, Maryam Sahraei ${ }^{2}$, Taha Fereydouni ${ }^{1}$, Zoha Khademi ${ }^{1}$

1. Internal Medicine, Arak University of Medical Sciences, Arak, IRN 2. Genetics, Arak University of Medical Sciences, Arak, IRN 3. Miscellaneous, Arak University of Medical Sciences, Arak, IRN 4. Microbiology, Arak University of Medical Sciences, Arak, IRN

$\square$ Corresponding author: Azam Ahmadi, ahmadia22@yahoo.com Disclosures can be found in Additional Information at the end of the article

\section{Abstract}

\section{Background}

The nucleotide excision repair (NER) system is one of the most important deoxyribonucleic acid (DNA) repair mechanisms and is critical for chemotherapy resistance. We conducted the present study to investigate the association between two polymorphisms of excision of repair crosscomplementing group 1 (ERCC1), the key component of the NER pathway, and the clinicopathological features of patients with non-small cell lung cancer (NSCLC).

\section{Methods}

A total of 38 patients with confirmed NSCLC were included in our study. DNA was extracted from peripheral blood. ERCC1 rs3212986 (8092) and rs11615 (118) were genotyped using molecular assays including polymerase chain reaction (PCR) with restriction fragment length polymorphism (by MboII and HpyCH4 enzymes) and sequencing.

\section{Results}

The PCR results indicated the correct performance of the genomics extraction and molecular protocols. The distribution of C/C, C/A and A/A genotypes at position 8092 was $42.10 \%, 47.36 \%$, and $10.52 \%$ respectively $(\mathrm{P}=0.03)$. Multivariate regression analysis showed that there was a significant correlation between C8092A (rs3212986) polymorphism and metastasis, grade of the tumor, and response to treatment. Individuals carrying the rs3212986 CA genotype and A allele had a significantly worse response to the treatment. Also, the correlation between alteration at this genomics location and patients with NSCLC who used to smoke cigarettes was positive. However, no significant association was detected between rs11615 C118>T polymorphism and demographic characteristics of patients with NSCLC.

\section{Conclusion}

Anoushirvani et al. This is an open access article distributed under the terms of the Creative Commons Attribution License CC-BY 3.0., which permits unrestricted use, distribution, and reproduction in any medium, provided the original author and source are credited.

We concluded that in lung cancer patients there is a relationship between tumor stage and rs3212986C >A polymorphism.

Categories: Genetics, Oncology

Keywords: nsclc, ercc1, sequencing, clinicopathological features 


\section{Introduction}

Every year, 1.35 million new cases and 1.18 million deaths are reported due to lung cancer [1]. Based on the cells affected by transformation, there are various forms of lung cancer; each form has its own symptoms and complications [2]. Although the genetic cause of this disease has not been identified properly, its relationship with the occurrence of changes in several genes has been proven. The products of each of these genes exist in different signaling pathways. Specialists have classified lung cancer into small cell lung cancer (SCLC), and non-small cell lung cancer (NSCLC) types according to the difference in their treatment [3]. Despite recent advances in cancer treatment, the survival rate for patients with lung cancer is very low, so its diagnosis by precise molecular methods is necessary [4]. One cause of cancer is the presence of defects in the genomics repair systems. One of the more important of these systems is the Nucleotide Excision Repair (NER) system [5-6]. Thymine dimers and large chemical complexes are the main targets of this system and are identified by this system. Repair by nucleotide extraction in eukaryotes and prokaryotes are largely similar; the only significant difference between these two methods is the number of removed nucleotides and involved enzyme complexes. One of the genes involved in the deoxyribonucleic acid (DNA) repair system by the NER method is excision repair cross-complementing group 1 (ERCC1) [7]. In the NER pathway, the product of the ERCC1 gene is necessary to repair DNA damages. The heterodimeric endonuclease ERCC1 mediates the incision on the 5-prime direction in the NER process. In addition, ERCC1 is involved in cross-link repair during the recombination process. Polymorphism of this gene plays a role in the carcinogenesis process. Polymorphism of this gene has been studied in many types of cancer in different populations [8-10]. The existence of single nucleotide polymorphisms (SNPs) in the key gene of the DNA repair system in breast cancer was identified in a study in 2018 [11]. A study in Japan in 2013 investigated polymorphism in three genomic regions including the ERCC1 gene in colorectal cancer [8]. In numerous studies, mutation and polymorphism in the hot-spots of the ERCC1 gene in relation to the NER system have been mentioned in other cancers including glioma, cervix, and bladder in different populations [12-14]. This gene has a length of 71,534 base pairs and many transcript variants. Codon 118 and nucleotide 8092 are two of the major areas susceptible to alteration in this gene.

This study evaluated the existence of polymorphism in tumor samples in relation to the clinical features of the affected population. These data will be important for the timely diagnosis of cancer and attaining the diagnostic biomarkers of lung cancer in early stages.

The aim of this study was to investigate polymorphism in the mentioned areas, converting nucleotide $\mathrm{C}$ to $\mathrm{A}$ at position 8092 (rs3212986) and exchanging nucleotide $\mathrm{C}$ with $\mathrm{T}$ at codon 118 (rs11615) in the ERCC1 gene in patients with lung cancer.

\section{Materials And Methods}

\section{Sample collection}

The clinical sample collection procedure was approved by the ethics committee of Arak University of Medical Science, Arak, Iran (IR.ARAKMU.REC.1396.7). A total of 38 blood samples from patients with lung cancer was obtained from Khansari Hospital, Arak, Iran.

\section{Polymerase chain reaction}

DNA was extracted using PZP Molecular IVD (Iran) according to the manufacturer's instructions. We used $50 \mathrm{ng}$ of Genomic DNA for polymerase chain reaction (PCR) using Taq DNA Polymerase Master Mix Red (Ampliqon) in a thermal cycler machine (Eppendorf, Germany). The primer sequences [10] used in the amplification reaction are presented in Table 1 . 


\section{Cureus}

\begin{tabular}{|c|c|c|}
\hline Primer ID & Sequence (5'-3') & Product size \\
\hline ERCC1 118-F & GCAGAGCTCACCTGAGGAAC & \multirow{2}{*}{$200 \mathrm{bp}$} \\
\hline ERCC1 118-R & GAGGTGCAAGAAGAGGTGGA & \\
\hline ERCC1 8092-F & TGAGCCAATTCAGCCACTAGAG & \multirow{2}{*}{$255 \mathrm{bp}$} \\
\hline ERCC1 8092-R & СTTTAGTTCCTCAGTTTCCCG & \\
\hline
\end{tabular}

\section{TABLE 1: Primer sequences used in this study}

For negative control, a sample without genomic DNA was used. We used a horizontal electrophoresis system to evaluate the accuracy of the produced amplicons after the reaction at an annealing temperature of $59.9^{\circ} \mathrm{C}$.

\section{Restriction fragment of length polymorphism and sequencing}

To investigate the occurrence of mutations in nucleotides 8092 and 118 of the ERCC1 gene, the amplicons produced were digested by MboII and $\mathrm{HpyCH} 4$ enzymes (Fermentas) at $37^{\circ} \mathrm{C}$ for three hours for restriction fragment of length polymorphism (RFLP) and sequencing. The inactivation of these reactions was carried out at $65^{\circ} \mathrm{C}$. Some amplicons were sent for sequencing with the ABI Applied Biosystem-Model 3730XL device (Macrogen CO., South Korea).

\section{Statistics analysis}

Data were analyzed using Chromas, Mega, EditSeq, BLAT, and an HWE test calculator. Conservation was evaluated via the UCSC Genome Browser. The difference between the groups was compared by one-way analysis of variance test using GraphPad Prism software version 7.0. The $P$ values $<0.05$ were considered statistically significant.

\section{Results}

In this case-control study, 38 lung cancer and 38 control samples were obtained with coordination and correspondence. Patient and control ages ranged from 33 to 75 years (Table 2). 


\section{Cureus}

\begin{tabular}{|c|c|c|c|c|c|c|c|c|c|c|c|}
\hline \multirow{2}{*}{$\begin{array}{l}\text { Characteristic } \\
\text { Total number of patients }\end{array}$} & \multirow{2}{*}{$\begin{array}{l}\text { Detail } \\
\text { NSCLC }\end{array}$} & \multicolumn{2}{|c|}{$\begin{array}{l}\text { No. of patients } \\
n(\%)\end{array}$} & \multicolumn{2}{|c|}{ CC n(\%) } & \multicolumn{2}{|c|}{ CA n(\%) } & \multicolumn{2}{|c|}{ AA n(\%) } & \multicolumn{2}{|c|}{$\begin{array}{l}\text { (CA \& AA) } \\
n(\%)\end{array}$} \\
\hline & & 38 & 100 & 16 & 42.10 & 18 & 47.36 & 4 & 10.52 & 22 & 57.89 \\
\hline \multirow{2}{*}{ Median age, range } & $\leq 58$ & 18 & 48 & 8 & 21.05 & 8 & 21.05 & 2 & 5.26 & 10 & 26.31 \\
\hline & $>58$ & 20 & 52 & 9 & 23.68 & 9 & 23.68 & 2 & 5.26 & 11 & 28.94 \\
\hline \multirow{2}{*}{ Gender } & Male & 30 & 80 & 12 & 31.57 & 15 & 39.47 & 3 & 7.89 & 18 & 47.36 \\
\hline & Female & 8 & 20 & 5 & 13.15 & 2 & 5.26 & 1 & 2.63 & 3 & 7.89 \\
\hline \multirow{4}{*}{ T stage } & 1 & 6 & 16 & 5 & 13.15 & 0 & 0 & 1 & 2.63 & 1 & 2.63 \\
\hline & 2 & 9 & 24 & 4 & 10.52 & 3 & 7.89 & 2 & 5.26 & 5 & 13.15 \\
\hline & 3 & 11 & 28 & 2 & 5.26 & 8 & 21.05 & 1 & 2.63 & 9 & 23.68 \\
\hline & 4 & 12 & 32 & 3 & 7.89 & 8 & 21.05 & 1 & 2.63 & 9 & 23.68 \\
\hline \multirow{3}{*}{ N stage } & 0 and 1 & 12 & 32 & 11 & 28.94 & 0 & 0 & 1 & 2.63 & 1 & 2.63 \\
\hline & 2 & 8 & 20 & 4 & 10.52 & 3 & 7.89 & 1 & 2.63 & 4 & 10.52 \\
\hline & 3 & 18 & 48 & 2 & 5.26 & 15 & 39.47 & 1 & 2.63 & 16 & 42.10 \\
\hline \multirow{2}{*}{ Metastasis } & Yes & 24 & 64 & 10 & 26.31 & 12 & 31.57 & 2 & 5.26 & 14 & 36.84 \\
\hline & No & 14 & 36 & 7 & 18.42 & 6 & 15.78 & 1 & 2.63 & 7 & 18.42 \\
\hline \multirow{3}{*}{ Response to therapy } & Partial & 5 & 12 & 0 & 0 & 5 & 13.15 & 0 & 0 & 5 & 13.15 \\
\hline & $\begin{array}{l}\text { Stable \& } \\
\text { progressive }\end{array}$ & 21 & 56 & 7 & 18.42 & 13 & 34.21 & 1 & 2.63 & 14 & 36.84 \\
\hline & Non-evaluable & 12 & 32 & 5 & 13.15 & 6 & 15.78 & 1 & 2.63 & 7 & 18.42 \\
\hline \multirow[t]{2}{*}{ Smoker } & Yes & 9 & 24 & 3 & 7.89 & 5 & 13.15 & 1 & 2.63 & 6 & 15.78 \\
\hline & No & 29 & 76 & 14 & 36.84 & 12 & 31.57 & 3 & 7.89 & 15 & 39.47 \\
\hline $\begin{array}{l}\text { Total number of control } \\
\text { group }\end{array}$ & $\begin{array}{l}\text { control (non- } \\
\text { patient) }\end{array}$ & 38 & 100 & 8 & 21.05 & 22 & 57.89 & 8 & 21.05 & 30 & 78.94 \\
\hline
\end{tabular}

\section{TABLE 2: Characteristics of collected samples and relation with haplotypes of 8092}

NSCLC, non-small cell lung cancer.

\section{PCR and RFLPS results}

The PCR-RFLPS results showed the accuracy of primer designing and performance of amplification reaction (Figures $1 A, 1 B, 1 C, 1 D$ ). 


\section{Cureus}
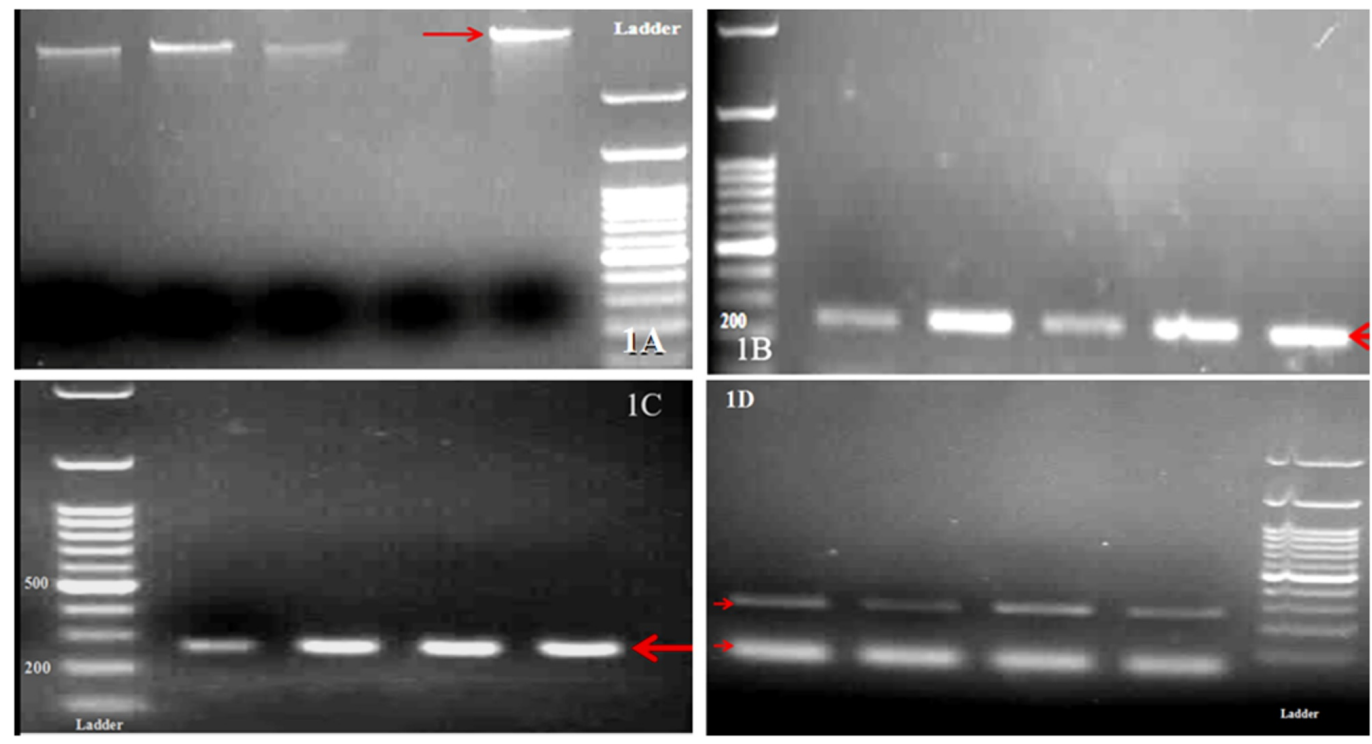

FIGURE 1: A. Extracted DNA from clinical samples.B.

Amplicons associated with codon 118 of the ERCC1 gene. 1C. Amplicons associated with position 8092 of the ERCC1 gene. 1D. Products from the enzymatic digestive reaction. Digestion with Mboll created 158bp (C/C), 41-117-158bp (C/A), and 41-117 bp (AA) at 8092 of ERCC1

\section{ERCC1 sequencing result}

The sequences were evaluated using various software (Figure 2).

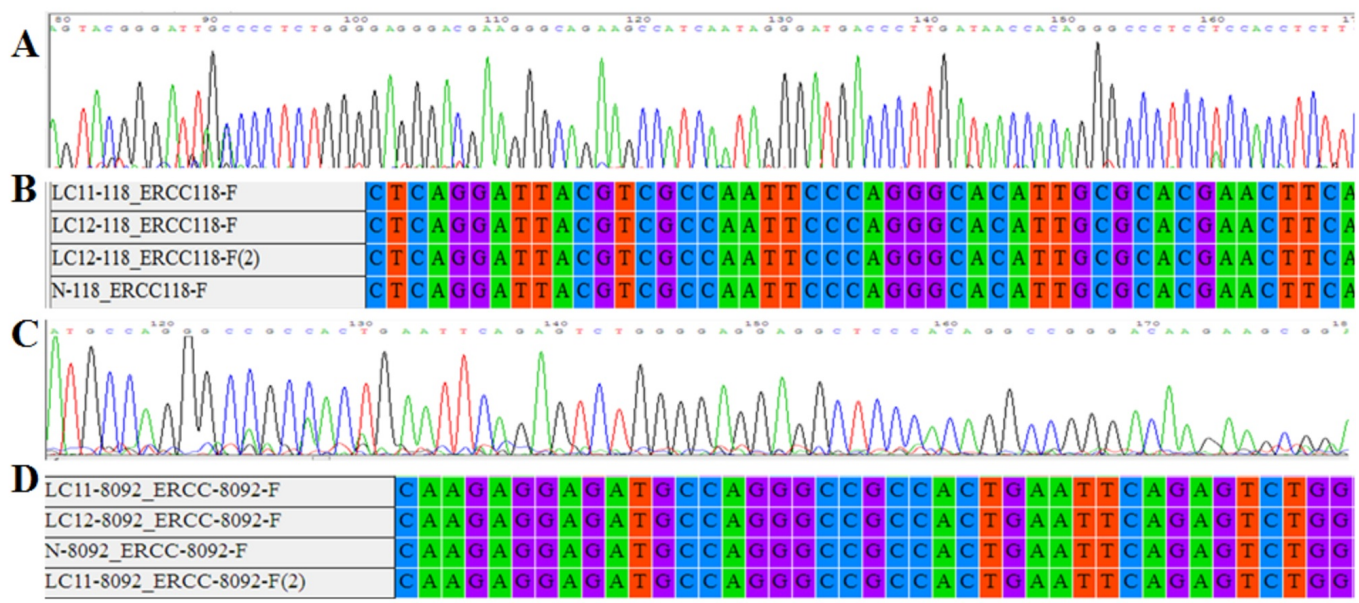

FIGURE 2: A, B. A screenshot of the CHROMAS and MEGA4 software associated with the sequences of codon 118 of the ERCC1 gene.C,D. A screenshot of the CHROMAS and MEGA4 software related to the 8092 position of the ERCC1 gene 


\section{Cureus}

The distribution of $\mathrm{C} / \mathrm{C}, \mathrm{C} / \mathrm{A}$, and $\mathrm{A} / \mathrm{A}$ genotypes at the 8092 position in the patient group was $42.10 \%, 47.36 \%$, and $10.52 \%$, respectively $(\mathrm{P}=0.03)$ (Table 3$)$.

\begin{tabular}{|c|c|c|c|c|c|c|c|}
\hline Row & $\begin{array}{l}\text { Pattern from digestion } \\
\text { reaction }\end{array}$ & Band (bp) & Genotype & $\begin{array}{l}\text { Patients } \\
(\%)\end{array}$ & OR & $\begin{array}{l}95 \% \text { confidence } \\
\text { interval }\end{array}$ & $\begin{array}{l}P \\
\text { value }\end{array}$ \\
\hline 1 & Template A & 158 & $\begin{array}{l}\text { CC } \\
\text { homozygote }\end{array}$ & 42.10 & 2.65 & 1.43 to 4.92 & $\begin{array}{l}\mathrm{P}< \\
0.05\end{array}$ \\
\hline 2 & Template B & $\begin{array}{l}158,41 \\
117\end{array}$ & $\begin{array}{l}\text { CA } \\
\text { heterozygote }\end{array}$ & 47.36 & 0.67 & 0.38 to 1.16 & $\begin{array}{l}P< \\
0.05\end{array}$ \\
\hline 3 & Template C & 41,117 & $\begin{array}{l}\text { AA } \\
\text { homozygote }\end{array}$ & 10.52 & 0.41 & 0.95 to 0.18 & $\begin{array}{l}P< \\
0.05\end{array}$ \\
\hline
\end{tabular}

\section{TABLE 3: Patterns from digestion reaction using Mboll enzyme}

OR, odds ratio.

This distribution of the control group at 8092 was $21.05,57.89$, and 21.05. However, no significant association was detected between rs11615 C118>T polymorphism and demographic characteristics of NSCLC. In the patient group at the 8092 position of the ERCC1 gene, the C allele frequency was 0.66 and the A allele frequency was 0.34 (Hardy-Weinberg Equilibrium calculator: Chi-square $=0.48693, \mathrm{P}<0.05$ ). These frequencies in the control group were 0.46 and 0.54 , respectively. The relationship between the clinicopathological properties of clinical samples and the occurrence of mutations in the involved hot-spots of the ERCC1 gene.

The properties of clinical samples and two SNPs of ERCC1 were evaluated by using GraphPad Prism software version 7.0. In our samples, a higher percentage of CA and AA polymorphisms yielded increased tumor grade (red color, $\mathrm{P}<0.01$, Pearson $\mathrm{r}$ analysis, $\mathrm{r}=0.99$, R squared: 0.99 ), lymph node involvement (blue color, $\mathrm{P}<0.01$, Pearson $\mathrm{r}$ analysis, $\mathrm{r}=0.89$, R squared: 0.79 ) and metastasis (green color, $\mathrm{P}<0.01$, Pearson $\mathrm{r}$ analysis, $\mathrm{r}=0.96$, R squared: 0.93 ) (Figure 3). 


\section{Cureus}

\section{Repeated measures one-way ANOVA data}

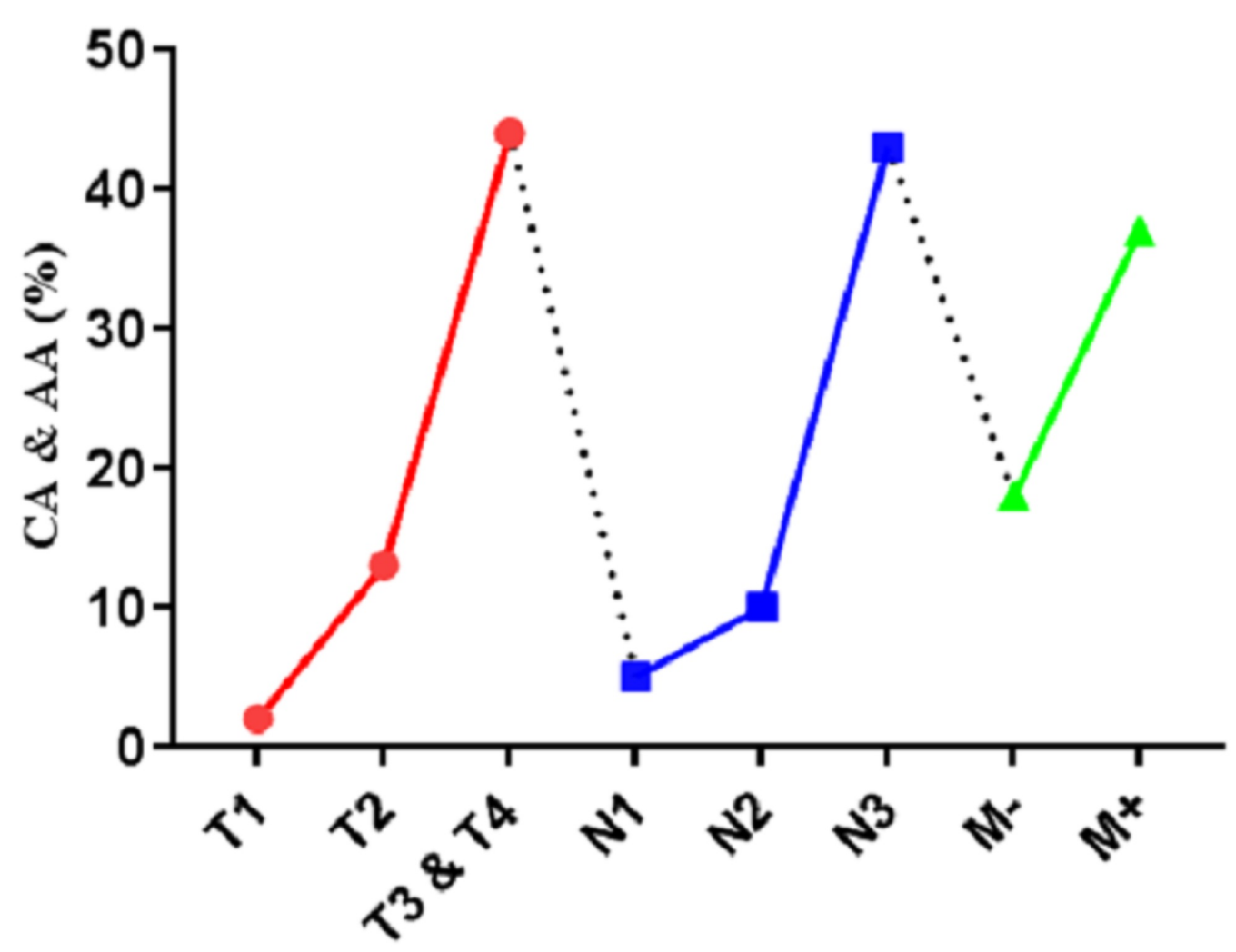

TNM

\section{FIGURE 3: Direct relationship between grade of tumor and metastasis}

TNM (Tumor, lymph-Node, Metastasis) frequency of C8092A polymorphism of ERCC1 gene of clinical samples $(P<0.05$, repeated measures of one-way analysis of variance data

All these relationships were statistically significant $(\mathrm{P}<0.05$, Pearson $\mathrm{r}$ analysis, $\mathrm{r}=0.95, \mathrm{R}$ squared: 0.9037). Also, our study showed that rs11615 SNP did not correlate with the TNM Classification of Malignant Tumors (TNM) stage.

\section{Discussion}

There are several forms of lung cancer. Genomic profiles in NSCLC, performed by comparative genomic hybridization analysis and microarray, have identified gene conflicts and different signaling pathways. Several SNPs have been implicated in genetic susceptibility to cancer. A review study in 2009 examined 1,836 articles from 1986 to 2008 related to genes involved in cancer. Some of these genes are commonly associated with lung cancer [15]. In a study by Zhou et al. in 2004 related to the survival of patients with lung cancer, two main points in ERCC1 including codons 118 and 8092 were identified by studying ERCC1 genotyping [16]. We conducted the present case-control study to investigate the association between two polymorphisms at ERCC1 (118 and 8092) with some clinicopathological features of NSCLC patients such as age, gender, TNM stage, response to therapy and smoking status in the Markazi province of Iran. 
A study by Tang et al. in 2014 investigated the existence of SNPs in the replication rate of key genes in lung cancer. Single nucleotide mutations, including polymorphisms of epidermal growth factor receptor (EGFR), KRAS proto-oncogene, GTPase (KRAS), and rearrangements of the ALK receptor tyrosine kinase (ALK) gene, are also involved in the occurrence of low-grade metastatic adenocarcinoma-type lung cancer [17]. In the same year, another meta-analysis study explained that polymorphism of rs11615 in ERCC1 gene correlates with diagnostic applications [18-19]. In our study, the rate of metastasis and involvement of lymph nodes in patients with modified 8092 positions of ERCC1 were 1.46- and 8.2-fold higher, respectively, than the wild-type haplotype. Previous studies have shown that deregulation of ERCC1 is associated with resistance to chemotherapy and ionizing radiation. A study in 2009 mentioned the relationship between ERCC1 and platinum treatment in NSCLC [4]. A study in 2013 investigated the effect of polymorphism in multiple genes on clinical outcomes in patients with colorectal cancer [8]. A study by Eggert et al. in 2015 investigated the relationship of genetic variations in nucleotide binding oligomerization domain containing 1 / caspase recruitment domain4 (NOD1/CARD4) and NOD2/CARD15 genes with a high risk of lung cancer [12]. Results of our study showed that a lower response to chemotherapy is related to a modified haplotype of 8092 rather than a wild-type variant (1.94 x).

The role of leptin receptor gene polymorphism in determining the sensitivity and diagnosis of NSCLC-type lung cancer in the population of affected people in China was also reported by Li et al. in 2012 [20]. Studying the effect of polymorphism on the process of identifying the susceptibility to various cancers, including lung cancer, is very important. In cases where the ERCC1 gene is mutant, the repair system will not be functional. On the other hand, the repair system can be one of the mechanisms of resistance to chemotherapy [16]. As shown in the studies mentioned above, identifying the changes in different codons of the ERCC1 gene is an important issue; consequently, identifying these changes in different populations is necessary.

In studies conducted on various types of cancers, polymorphisms in key genes involved in cancer are directly related to their diagnosis and treatment. Understanding the meaning and concept of polymorphism will lead the doctor to more successful treatment because personalized medicine is performed based on polymorphisms [21]. For example, the relationship between the response to chemotherapy and polymorphism of G4C14 into A4T14 p73 in the exon 2 position in lung cancer was investigated by Li et al. in 2004 [22]. Identifying polymorphism of the angiotensin I converting enzyme (ACE) gene helps determine whether to prescribe the drug Captopril [23]. Detecting polymorphism of the vitamin D receptor (VDR) and forkhead box P3 (FOXP3) genes plays a role in prescribing vitamin D supplements [24]. Diagnosing serotonin transporter (SERT) gene polymorphism is effective in prescribing the drug Fluoxetine [25]. The results of this study align with those mentioned above to help identify cancer and provide successful treatment.

As shown in Table 2, TNM scores in individuals with modified 8092 (CA and AA) were 3.4x, 8.2x and 1.46x higher, respectively, than those for individuals with the CC haplotype. Therefore, surveying a patient's ERCC1 gene at codon 8092 can likely indicate the patient's progressive state of NSCLC. The results of this study indicate a significant relationship between the presence of C8092A polymorphism of the ERCC1 gene and the pathological characteristics of patients with NSCLC with partial or no treatment response rates. Also, there is a positive correlation between alteration at this genomics location and persons with NSCLC who smoke cigarettes. However, there was no significant association between clinicopathological characteristics of NSCLC and 118 polymorphism.

The tumorigenesis process of lung cancer is associated with several factors, including cigarette smoke and contaminated air. The samples used were collected from Arak city, which is one of the most contaminated and industrial cities of Iran. Thus, the present study will be additionally important from the epidemiological view, although a larger group should be studied. Our 
multivariate regression analysis with GraphPad Prism showed a positive correlation between alteration at this genomics location (C8092A) and persons with NSCLC who used to smoke cigarettes.

The ERCC1 gene has a critical role in the repair system. The NER system can be one of the mechanisms of resistance to chemotherapy, so identifying changes in different populations is necessary. The importance of identifying changes in different codons of the ERCC1 gene has been shown in many studies. Therefore, future studies will be necessary to evaluate the expression of this gene in ribonucleic acid (RNA) and protein levels.

\section{Conclusions}

The results of the present study determined a probable correlation between patients' TNM cancer stage and responses to treatment for patients with C8092A polymorphism of ERCC1. Therefore, identifying these changes in different populations can be critical before starting treatment.

\section{Additional Information \\ Disclosures}

Human subjects: Consent was obtained by all participants in this study. IR.ARAKMU.REC.1396.7 issued approval IR.ARAKMU.REC.1396.7. The clinical sample collection procedure was approved by the ethics committee of Arak University of Medical Science, Arak, Iran (IR.ARAKMU.REC.1396.7). . Animal subjects: All authors have confirmed that this study did not involve animal subjects or tissue. Conflicts of interest: In compliance with the ICMJE uniform disclosure form, all authors declare the following: Payment/services info: All authors have declared that no financial support was received from any organization for the submitted work. Financial relationships: All authors have declared that they have no financial relationships at present or within the previous three years with any organizations that might have an interest in the submitted work. Other relationships: All authors have declared that there are no other relationships or activities that could appear to have influenced the submitted work.

\section{Acknowledgements}

Ali Arash Anoushirvani and Reza Aghabozorgi contributed equally to the work.

\section{References}

1. Saadatian Z, Masotti A, Nariman Saleh Fam Z, Alipoor B, Bastami M, Ghaedi H: Singlenucleotide polymorphisms within microRNAs sequences and their 3' UTR target sites may regulate gene expression in gastrointestinal tract cancers. Iran Red Crescent Med J. 2014, 16:16659-10. 10.5812/ircmj.16659

2. Ni M, Zhang W, Qiu J, et al.: Association of ERCC1 and ERCC2 polymorphisms with colorectal cancer risk in a Chinese population. Sci Rep. 2015, 4:4112. 10.1038/srep04112

3. Ji G, Gu A, Xia Y1, et al.: ERCC1 and ERCC2 polymorphisms and risk of idiopathic azoospermia in a Chinese population`. Reprod Biomed Online. 2008, 17:36-41. 10.1016/S1472-6483(10)60290-8

4. Vilmar A: SørensenJB: Excision repair cross-complementation group 1 (ERCC1) in platinumbased treatment of non-small cell lung cancer with special emphasis on carboplatin: a review of current literature. Lung Cancer. 2009, 64:131-9. 10.1016/j.lungcan.2008.08.006

5. Liu L, Li CH, Jin TF, Xu DY: Study on the ERCC1 gene polymorphism response to chemotherapy and prognosis of gastric cancer. Genet Mol Res. 2014, 13:8722-8. 10.4238/2014.October.27.13

6. Zhang L, Wang J, Xu L, et al.: Nucleotide excision repair gene ERCC1 polymorphisms 
contribute to cancer susceptibility: a meta-analysis. Mutagenesis. 2012, 27:67-76. 10.1093/mutage/ger062

7. Gao R, Reece KM, Sissung T, et al.: Are race-specific ERCC1 haplotypes in melanoma cases versus controls related to the predictive and prognostic value of ERCC1 N118N?BMJ. Open. 2013, 3:002030. 10.1136/bmjopen-2012-002030

8. Kumamoto K, Ishibashi K, Okada N, et al.: Polymorphisms of GSTP1, ERCC2 and TS-3'UTR are associated with the clinical outcome of mFOLFOX6 in colorectal cancer patients. Oncol Lett. 2013, 6:648-54. 10.3892/ol.2013.1467

9. Dai Q, Luo H, Li XP, Huang J, Zhou TJ, Yang Z-H: XRCC1 and ERCC1 polymorphisms are related to susceptibility and survival of colorectal cancer in the Chinese population. Mutagenesis. 2015, 30:441-9. 10.1093/mutage/geu088

10. Xu ZC, Cai HZ, Li X, et al.: ERCC1 C118T polymorphism has predictive value for platinumbased chemotherapy in patients with late-stage bladder cancer. Genet Mol Res. 2016, 15. 10.4238/gmr.15027801

11. Anoushirvani AA, Aghabozorgi R, Ahmadi A, et al.: Association of rs1042522 SNP with clinicopathologic factors of breast cancer patients in the Markazi province of Iran. Open Access Maced J Med Sci. 2018, 6:2277-2282.10.3889/oamjms.2018.486

12. Eggert M, Aichinger E, Pfaffl MW, Steinlein OK, Pfob M: Nicotinic acetylcholine receptor subunits $\alpha 4$ and $\alpha 5$ associated with smoking behaviour and lung cancer are regulated by upstream open reading frames. PLoS One. Edited by. Mansvelder HD. 2013, 8:66157. 10.1371/journal.pone.0066157

13. Matullo G, Guarrera S, Carturan S, et al.: DNA repair gene polymorphisms, bulky DNA adducts in white blood cells and bladder cancer in a case-control study. Int J Cancer. 2001, 92:562-7. 10.1002/ijc. 1228

14. Bajpai D, Banerjee A, Pathak S, Jain SK, Singh N: Decreased expression of DNA repair genes (XRCC1, ERCC1, ERCC2, and ERCC4) in squamous intraepithelial lesion and invasive squamous cell carcinoma of the cervix. Mol Cell Biochem. 2013, 377:45-53. 10.1007/s11010013-1569-y

15. Chen P, Wiencke J, Aldape K, et al.: Association of an ERCC1 polymorphism with adult-onset glioma. Cancer Epidemiol Biomarkers Prev. 2000, 9:9-8.

16. Zhou W, Gurubhagavatula S, Liu G, et al.: Excision repair cross-complementation group 1 polymorphism predicts overall survival in advanced non-small cell lung cancer patients treated with platinum-based chemotherapy. Clin Cancer Res. 2004, 10:4939-43.10.1158/10780432.CCR-04-0247

17. Tang Y, He Z, Zhu Q, Qiao G: The 2011 IASLC/ATS/ERS pulmonary adenocarcinoma classification: a landmark in personalized medicine for lung cancer management. J Thorac Dis. 2014:589-96. 10.3978/j.issn.2072-1439.2014.09.15

18. Bandres E, Bitarte N, Arias F, et al.: microRNA-451 regulates macrophage migration inhibitory factor production and proliferation of gastrointestinal cancer cells. Clin Cancer Res. 2009, 15:2281-90. 10.1158/1078-0432.CCR-08-1818

19. Perdomo C, Campbell JD, Gerrein J, et al.: microRNA 4423 is a primate-specific regulator of airway epithelial cell differentiation and lung carcinogenesis. Proc Natl Acad Sci. 2013, 110:18946-51. 10.1073/pnas.1220319110

20. Li Y, Geng J, Wang Y, Lu Q, Du Y, Wang W, Li Z: The role of leptin receptor gene polymorphisms in determining the susceptibility and prognosis of NSCLC in Chinese patients. J Cancer Res Clin Oncol. 2012, 138:311-6. 10.1007/s00432-011-1098-6

21. Redekop WK, Mladsi D: The faces of personalized medicine: a framework for understanding its meaning and scope. Value Heal. 2013, 16:4-9. 10.1016/j.jval.2013.06.005

22. Li G, Wang LE, Chamberlain RM, Amos CI, Spitz MR, Wei Q: p73 G4C14-to-A4T14 polymorphism and risk of lung cancer. Cancer Res. 2004, 64:6863-6. 10.1158/0008-5472.CAN04-1804

23. Nakano Y: Angiotensin I-converting enzyme gene polymorphism and acute response to captopril in essential hypertension. Am J Hypertens. 1997, 10:1064-8. 10.1016/S08957061(97)00279-3

24. Neagu M, Constantin C, Caruntu C, Dumitru C, Surcel M, Zurac S: Inflammation: a key process in skin tumorigenesis (review). Oncol Lett. 2018, 10.3892/ol.2018.9735

25. Dreyer J-L: New insights into the roles of microRNAs in drug addiction and neuroplasticity . Genome Med. 2010, 2:92.10.1186/gm213 